\title{
Influence of Education Policies on Music Discipline's Performance of Basic Education in China
}

\author{
Weiyi Dai
}

University Of Shaoxing, Shaoxing, China

Corresponding author.86-17816535195/545208299@qq.com

\begin{abstract}
This paper focuses on school music education, especially the music discipline in primary and secondary school) benefits from some related policies, in recent years it has been pushed to a relative degree of climax. This article hold with the rich and authoritative theories, illustrating the importance of music education in the stage of basic education, to show readers how music education is subtly affecting children's learning and growth; By analyzing the status quo of music discipline in the primary and secondary schools that performing in the stage of nowadays school education and combing with the context of China's music education, and even the relations between policies and the development of music discipline appeared in the international education mode, the author will analyze to what extent education policies can affect the development of music discipline, and provide the valuable theoretical basic during the process of looking forward to the future music discipline can further infiltrate in to the basic education.
\end{abstract}

Keywords: school music education, music discipline, education policy, Chinese music education history, basic education stage

\section{INTRODUCTION}

The author started to explore the music education and launched a preliminary exploration in this field, by trying to indeed understand the purpose of music education during the process of learning and acquire the awareness of the necessity of learning music at the same time: the marginalization of music discipline in a few years ago was a serious problem under the influence of exam-oriented education mode, but its position gradually improved among the basic education benefited from some changes in policies every year which was also reflected in the curriculum evolution of higher school education.In the long process from receiving education to becoming an educator, the author has discovered some subtle changes in music discipline in primary and secondary schools along with the upgrading of public cognition, but it is conceivable that the transform caused by education policies that introduced by the government is more obvious. By drawing lessons from history and learning the international tendency, it is more inspiring to exploring the close relationship between education policy and the development of music discipline, so as to develop school music education and implement music to the public.

\section{THE CURRENT STATUS OF SCHOOL MUSIC EDUCATION UNDER THE INFLUENCE OF EDUCATION POLICY AT THE BASIC EDUCATION STAGE}

In recent years, school music education in China present a dynamic development feature. With the promotion of all-round quality education philosophy, the social perception of school music education has gone through a transfer process.

\subsection{Inadequate attention to school music education under the influence of examination system}

Throughout the five thousand long Chinese history, different examination systems were implemented in different eras. For example, the election system in Han Dynasty, the well-known imperial examination system in the Sui and Tang Dynasties, the eight shares of the people system in the Ming and Qing Dynasties and the college entrance examination system resumed in 1977. At the very beginning, the purpose of the examination system is to eliminate the old-fashioned thought of hereditary nobility but later it became the main channel 
for the government to select talents from all classes at both central and local government levels, which has been preserved to this day. The influence of the examination system is too profound and the culture of exam-oriented education formed accordingly. Although as early as in 1999, the central government issued Decision on Deepening Educational Reform and Promoting Quality Education in an All-round Way, the concept of quality education entered into public. However, it is still difficult to replace the perception that has been gradually rooted in people's mind: the ill concept of examination grades priority; the division of disciplines simply by the standard of examination types. Being categorized unfairly as a minor subject that examinations are not required, music discipline along with the other so-called minor subjects [6] have become insignificant accordingly at the basic education stage [2]. In the class hours of primary and middle school, music subject takes far fewer hours than the main subjects such as Chinese, Mathematics and English. Even the left few class hours may be handed to the other main subjects. This has caused a reduction in music teachers' enthusiasm and less importance attached to it [20]. In some grassroots areas, due to the poor quality of people's living standards, the music education resources cannot keep up with the first-class cities' equipment and music education in these areas are vacant [23].

\subsection{The lack of attention to the music discipline after the evolution of education}

However in recent years, the education policy has made some changes. The college entrance examination system has gone through reforms since 2017 in some pilot cities such as Jiangsu, Zhejiang and Shanghai. The reform aim is to realize the transfer from traditional exam-oriented education to quality education. The Ministry of Education and other nine departments have issued the notice on relieving students' study burdens. Especially in 2020 and 2021, the Ministry of Education officially issued a document, which clearly regulates that music education shall be included in the middle and high school entrance examinations. Meanwhile, children in the elementary and secondary schools are benefited from the "Double Reduction" Policy, which further promotes the all-round development of morality, intelligence, physical education, art and labor by suspending additional cultural lessons and reducing homework. An upsurge appeared in music education and even in grassroots areas some reforms has been conducted with the support of national policies. The transfer of ideas in short period is hard to realize. Therefore, the policy of transforming the pursuit of aesthetic education in children's cultivation to a compulsory requirement with the coordination of exams shows that related education department, school and parents should pay more attention to music subject when making training plans for all children.

\subsection{Changes in the importance of music subject after educational reform}

\subsubsection{The music syllabus for primary and secondary schools has been adjusted}

In order to actively reflect the educational concept of compulsory education music curriculum standard, the music class in primary and middle schools requires that students should carry out educational practice as the main body, and proposes to cultivate their music accomplishment at the same time ( students should gradually improve and master the music-culture in the process of music learning, sight-singing practice, multi-tone thinking ability, basic music theory, music performance and perception ability) as well as music aesthetic (requires students not only master the knowledge and skills from the emotional attitude, but also values deeper understanding and cultivates them to achieve independently beauty). The music curriculum in primary and secondary schools is no longer a unilateral indoctrination by teachers, but is driven by interests and emphasizes the practicality. Meanwhile, learning the methods and means from Dalcroz, Orff, Colvin and other educators as an auxiliary tool of teaching, so as to enlighten elementary and middle school students for reaching the cultivation of more diverse musical skills, thus achieving the important purpose of aesthetic education, promoting children in the process of learning aesthetic with thinking ability progression[8]. In order to "carry forward the Chinese nation traditional culture" as the era of educational subject, [18]the Ministry of Education has issued a series of policies, such as the Notice to Undertake Pilot Work of Peking Opera in Primary and Middle School Class, so that putting Beijing Opera into the stage of nine-year compulsory education (basis) of music course, music education of the programmatic document on the Compulsory Education Music discipline Standard has also conducted with the corresponding revision [3].

\subsubsection{Reform on the training program of music education in colleges and universities}

Most future career plans of college music education majors tend to divide music teachers with different segments. With the curriculum reform of music discipline in elementary and middle schools, colleges and universities should also make corresponding changes. It is vital to train those who can give children effective guidance in the process of music learning. According to the knowledge and ability that need to be mastered in primary and secondary schools, students majoring in music teaching are required to improve their own quality more comprehensively based on the curriculum outline issued by the Ministry of Education to colleges and universities [2]. 
In fact, since the founding of the People's Republic of China, the reform of music education in schools has been uninterrupted except for the unstable period (1967-1977) when the development of culture was hindered. Since 2001, China's music education has been undergoing great changes, seeking the best way to develop. Each change also leads to the innovation of people's educational concepts, value orientation and cognitive level. Because of the lower level of culture, economy and other aspects, the change in ideas of non-major cities is slower than that of major cities, which leads to the relatively backward development of music education in primary and secondary schools in non-major cities. Even if music is included in the examination system, it will be difficult to popularize music education and balance education resources in a short time. Thus, more detailed and targeted education policies are needed to further the development of music education [17].

\section{SIGNIFICANCE OF SCHOOL MUSIC EDUCATION IN BASIC EDUCATION}

Due to the great significance in the stage of basic education, school music education can carry out long-term reform and continuously improve its status in the reform.

In essence, school music education is a project to help nurture children. Teachers mobilize students' different feelings with different music teaching methods [1] and actively guide them to master certain music knowledge and skills so that they can continuously improve their emotional values and enhance personality cultivation during the long-term and repeated aesthetic development, which is exactly the goal of aesthetic education. The study of music can help to cultivate the children's language, reading, hands-on creation and other abilities in the specific operation stage and the formal operation stage, so that they can develop good living habits and intelligence is also better cultivated [12], laying the foundation for future learning tasks. Compared with other children, children who accept music education are not necessarily more intelligent, but they must but they must have strong divergent thinking ability, aesthetic ability [16], creative ability, collective consciousness and cooperation ability and other comprehensive qualities [2].

\section{THE IMPACT OF POLICIES ON MUSIC EDUCATION PRESENTED IN THE HISTORY OF CHINESE MUSIC EDUCATION}

Music education has a long history, people can trace its origin by looking back to the period of "Xia", "Shang", "Zhou", which was a symbol of the beginning of school music education in China: Music education prevailed in the ruling class, in order to make the successors of ruling classes better learn to rule, music education was transformed from the instrument of commanding the religious authority to the measures with education effects [10]. Then it comes to the period of letting a Hundred Schools of Thought Contend, music education further developed because of the "bad" ceremony music system appearing. The educators represented by Confucius popularized the music education that was originally acceptable to the ruling class to upgrade the ideological and the cultural accomplishment of the masses, helping cultivate national benevolence and stabilize the community of the country. The development of music education reached a peak in the Tang Dynasty [11] when a period witnessed the heyday of economic, cultural, political and military development, which happened to be the internal driving force for the advancement of music education. In the early period of Tang Dynasty for ending up wars and chaos the people urgently needed rehabilitation, the ruling class with high artistic attainment advocated to vigorously develop music industry, resulting in the establishment of relevant music education institutions [4] from the central and local governments. Similar to imperial examination system, the mechanism for selecting music talents was aimed to continuously enhance national music culture and aesthetic quality, and facilitate exchanges between countries, thereby highlighting the splendid culture and art of the country [19]. The poetry of the Tang Dynasty is the gorgeous cultural heritage of the Chinese nation. Supplementing with music, they have been widely circulated, so that ordinary people have received cultural education, and improved their music literacy. Not only in terms of the taste of life and aesthetic ability, the realm of aesthetic education has also been unprecedentedly expanded. The author believes that the development of music education in Tang Dynasty can serve as the best reference: as a medium for the ruling class to wield power in Xia, Shang and Zhou dynasties, music education was launched and promoted on a nationwide scale (the scope from central to local, from the ruling class to the common people) according to different views of the ruling class with the change in the political situation. Therefore, music education under step-by-step development in the previous period has been pushed to its peak.

The presence of policy during the development of music education can be dated back to the modern period of China [22]. In the 1860s, after initiating the Westernization Movement, the government realized that it is the right solution to save the country by "learning from the foreigners to compete with them". In the process of learning, it is noted that countries such as Europe, Japan, and other countries attached great importance to music education, which can also be developed into an essential measure to rejuvenate 
Chinese nation. Music can invigorate people's spirit and convey new ideas to Chinese people. In that period, in order to recover its status and stand up again, China needed to change the ideology of the entire country, and started to strengthen the impact of school education on society [5], thus gradually developing school music as a result. Music educators integrated music with patriotism thoughts, in hope of encouraging a new generation of teenagers to study and create hard by carrying out singing activities. Gradually, this has changed the mindset of Chinese people in the course of learning and expressing music [21].

As mentioned in the previous part, Western countries attach great importance to music education. The author believes that music education in China has developed unremittingly. However, influenced by political situations at different stages, compared with Western countries, China has lagged behind at the level of music culture, economic and development levels, resulting in their advancement to a certain degree. By the 20th century, Francis Roscher issued the results of experimental research in American Psychological Association, and stated that " preschool-age children who have performed long-term music-related exercises several times within a week would acquire $46 \%$ higher spatial intelligence scores than those receiving no music education." Soon, the United States quickly passed Education America Act and National Standards for Arts Education, and listed art education as a core school discipline, aiming to help children master the knowledge and skills by analogy, creativity and innovative thinking by virtue of art education. In addition, the United States was earlier than China to include art in the graduation assessment at the elementary education stage in nearly 40 states [13]. Russia and the United Kingdom also issued music education curriculum standards very early. Students are required to master music knowledge, learn music appreciation, and actively participate in chorus and other public music courses chorus during the period of elementary and junior high school education. After 1999, China closely kept in pace with international education and launched policies to improve the music discipline norms successively [7].

\section{CONCLUSION}

The formulation of policies in the context of the music education history in China has far-reaching influence on the development of music education. In past years, entrance examination policies had, to some extent, restricted the scope of study of educates, causing the imbalance in the emphasis of different subjects, hindering the education of aesthetic, ideology and morality education. The author hopes that, in the future, policies will directly improve the imbalanced development among subjects and the marginalization of music education; Quality-oriented education will be truly implemented in the long future, music education will be popularized in all classes and regions, especially in regions where educational resources are scarce; Policies are made in favor of these grassroots schools to improve their orientation of music education and financial support will be provided to develop music education.

The music discipline and even aesthetic education shall be integrated into the training plan of students in primary and secondary schools. Policies shall also be improved in the process of the constant improvement and standardization of the curriculum syllabus, and the planned and targeted teaching, so as to adapt to the change of the education circle, assist the development, coordinate and supervise the implementation of policies.

Music education, with the assistance of policies in the continuous development of the stages of primary and secondary schools, is playing the role of cultivating children's intelligence, creative and language ability, ideological and moral standards, and even inheriting the traditional Chinese cultures [15]. Meanwhile, it enables citizens to recognize the civilization of Etiquette Music Makes a Country Progress [4]. For the better development of the society and to realize the great Chinese Dream, therefore, the author reckons that we should pay more attention to aesthetic education, constantly make efforts for exploring a better path of music education, lead people from all classes to a better future from cultivating the good ideological and moral character and improving the aesthetic education of the new generations [14].

\section{REFERENCES}

[1] Dong, L. Cultivation of creativity in children's music activities[in Chinese]Education Research, 2020, 3(5). https://doi.org/10.32629/er.v3i5.2736

[2] Dongjie, R. Research on the Methods of Training Students' Innovative Ability by Music Education in Primary and Middle Schools[in Chinese] Song of the Yellow River, 2019, 548, Available: http://kns.cnki.net/kcms/detail/detail.aspx?doi=10.1 9340/j.cnki.hhzs.2019.23.088

[3] Danqin, W Strategies for inheritance of regional music culture in music education in primary and middle schools. In: 2018 International Conference on Education, Psychology, and Management Science (ICEPMS 2018), 2018. http://dx.doi.org/10.25236/icepms.2018.237

[4] Hanhan, L. The influence of Education System in Tang Dynasty on Music Education.[in Chinese] Popular Literature, 2013(17):258

[5] Huizi, C. The historical epitome of Chinese modern music education-rereading Sun Jinan's "Annuals of 
Modern Chinese Music Education History (1840-2000)" (Revised Edition).[in Chinese] Journal Of Nanjing Arts Institute(Music \& Performance), 2019, 000(001): 141-144

[6] Lian, Z. Research on the status quo and methods of music education in Elementary and Secondary Schools.[in Chinese] Popular Literature, 2011(05): 216-217

[7] $\mathrm{Li}, \mathrm{F}$ and $\mathrm{Xu}, \mathrm{L}$. Research on the european and american music education mode and corresponding influence on the chinese native music education. Proceedings of the 2015 Conference on Informatization in Education, Management and Business. 2015. http://dx.doi.org/10.2991/iemb-15.2015.73

[8] Lan, Z. A Probe into the Value of Orff's Music Teaching Mode Used in Primary School Music Classes. International Education Forum, 2020, 2(10):101. https://doi.org/10.32629/jief.v2i10.2268

[9] Ming, C, Ling, H and Wei, Y. On the Vocational Reform of Music Teaching in Colleges and Universities[in Chinese] 。 Literary Forum, 2014(09): 193

[10] Qianru, L. The Analysis of the devolopment of music education in China[in Chinese] Drama House[A],1007-0125(2016)08-0193-01

[11] Ruifang, T. A Probe into the Inner Motivation of Music Prosperity in the Tang Dynasty[in Chinese]. 2014, October, Available: http://www.cnki.net/kcms/doi/10.16565/j.cnki.1006 $-7744.2014 .30 .016 . h t m l$

[12] Shanshan, L. The Influence of Early Music Education on Children's Comprehensive Ability[in Chinese] Music Times, 2015(07): 95-96

[13] Tong, W. Policy Incentives and Evaluation Standards: Two Key Points of Music Education in U.S. Elementary and Secondary Schools[in Chinese] SHANGDONG\&ARTS, 2021(01): 49-53

[14] Tingting, Z. On the relationship between social music cultural environment and citizenship[in Chinese] Northern Music 2017: 314, 244, 248

[15] Tao, Z. The School Music Education.[in Chinese] DAGUAN, 2015(6)

[16] Xiaoshen, Z. The influence of music education on children's development[in Chinese] Popular Literature 2015(05): 228

[17] Xing, Z. The development path on aesthetic education policy for primary and secondary schools in China. In: 2020 International Conference on Modern Education and Information Management
(ICMEIM), 2020: 352-356, doi: 10.1109/ICMEIM51375.2020.00087.

[18] Xu, H. School Music Education and the Inheritance of Traditional Music Culture[in Chinese]. Song of the Yellow River,2014, 000(001):34-35

[19] Xiaojun, L. The Social Cause and Influence of the Prosperity of Music and Dance in Tang Dynasty [in Chinese]. February, 2014. Available: http://www.cnki.net/Kim's/doi/10.16565/j.cnki.100 6-7744.2014.06.019.html

[20] Xinming, F. Investigation on the Status Quo of Music Education in Elementary and Secondary Schools [in Chinese]. Northern Music, 2018(11): 155.

[21] Yan, Q. The Important Role of School Songs in Modern Chinese Music Education [in Chinese]. Northern Music, 2017(15): 180.

[22] Yan, Z.(2018). The development of Modern Music Education in China [in Chinese]. Drama House, 1007-0125(2018007-0136-02.

[23] Zhenbang, H, Xiaohua, $Z$ and Zhishan, G. Investigation and Analysis of the Status Quo of Music Education in Rural Primary and Secondary Schools in Henan Province under the Background of New Curriculum[in Chinese]. Big Stage, 2011(10): 154-15. 